\title{
Predictions of Friction Coefficient in Hydrodynamic Journal Bearing Using Artificial Neural Networks
}

\author{
Dragan Milčić1, ${ }^{*}$ - Amir Alsammarraie ${ }^{2}$ - Miloš Madić1 - Vladislav Krstić 3 - Miodrag Milčić1 \\ ${ }^{1}$ University of Niš, Faculty of Mechanical Engineering, Serbia \\ 2 Tikrit University, Engineering Faculty, Iraq \\ ${ }^{3}$ Ljubex International, Belgrade, Serbia
}

This paper explores the influence of the frequency of shaft sleeve rotation and radial load on a journal bearing made of tin-babbitt alloy (Tegotenax V840) under hydrodynamic lubrication conditions. An experimental test of the frictional behaviour of a radial plain bearing was performed on an originally developed device for testing rotating elements: radial and plain bearings. Using the back-propagation neural network, based on experimental data, artificial neural network models were developed to predict the dependence of the friction coefficient and bearing temperature in relation to the radial load and speed. Using experimental data of the measured friction coefficient with which the artificial neural network was trained, well-trained networks with a mean absolute percentage error on training and testing of $0.0054 \%$ and $0.0085 \%$, respectively, were obtained. Thus, a well-trained neural network model can predict the friction coefficient depending on the radial load and the speed.

Keywords: artificial neural network, hydrodynamic journal bearing, babbitt metal tin-based alloy, friction coefficient

\section{Highlights}

- An artificial neural network was used to predict the friction coefficient of the hydrodynamic radial journal bearings.

- For the training and testing of artificial neural network (ANN), experimental data obtained by testing radial hydrodynamic journal bearings made of a tin-Babbitt alloy (Tegonenax V840) were used.

- The ANN model allows the prediction of the friction coefficient based on the radial load of the bearing and the speed.

- Prediction of the coefficient of friction using ANN has proven to be a competitive and efficient method.

\section{O INTRODUCTION}

Hydrodynamic bearings support a rotating shaft with its associated loads, through a pressure field developed within the lubricant that separates the solid surfaces. Journal bearings made of tin-babbitt alloy (Tegotenax V840) under hydrodynamic lubrication conditions are widely used in compressors, turbines, pumps, electric motors, electric generators, mining ore crushers, etc. Sliding friction in the contact surfaces between the material of the shaft and the sleeve material is a dissipative process of a complex nature, accompanied by a series of phenomena: mechanical, physicochemical, electrical, metallurgical, and thermal characteristics, which lead to the wear and tear of coupled bodies.

The coefficient of friction is significantly influenced by: normal load, geometry, relative surface motion, sliding velocity, the surface roughness of the rubbing surfaces, the type of material, system rigidity, temperature, stick-slip, relative humidity, lubrication and vibration.

Among these factors, normal load and sliding velocity are the two major factors that play significant roles in the variation of the friction coefficient [1] to [4].
The effect of radial load on the friction coefficient and loss material of different polymer and composite materials was investigated [2]; it was found that the amounts of friction coefficient and loss material are different for different materials. The tribological actions of Babbitt alloy 16-16-2 sliding against aluminium bronze $\mathrm{ZnCuA19Mn2}$ lubricated by seawater were systematically investigated by Wu et al. [3]. The results indicated that the friction coefficient decreased as the load increased to $30 \mathrm{~N}$ and then remained steady at high loading but decreased with an increase in sliding speed. Zeren et al. [4] studied the tribological behaviour of two different tin-based bearing materials in dry sliding conditions: one of these alloys with low $\mathrm{Sb}$ content $(7 \%)$ is known as SAE 12 and is widely used in the automotive industry and the other with a high Sb content (20\%) is an $\mathrm{Sn}-$ $\mathrm{Sb}-\mathrm{Cu}$ alloy. Although search results have proved that WM-2 and WM-5 alloys can be used in dry sliding conditions, it is shown that the performance of WM-5 under heavy service conditions is better than WM-2 due to its alloying elements.

Artificial neural networks (ANN) are a successful tool for predicting some tribological properties. ANN is a mathematical model inspired by the biological nervous system. ANN technology is used to solve 
complex scientific and engineering problems. The significance of this technology is that ANN models can be trained based on experimental data to recognize solutions. The ANN prediction method has been used in several applications, such as wear and friction.

Asafa and Fadare [5] have presented an ANN predictive model that captures the dynamic behaviour of the tool wear and can be deployed effectively for online monitoring processes. Nine different structures of multi-layer perceptron neural networks with feedforward and back-propagation learning algorithms were designed using the MATLAB neural network toolbox. An optimal ANN architecture of 5-12-4-2 with the Levenberg-Marquardt training algorithm and a learning rate of 0.1 was obtained using the Taguchi experimental design method. Durmuş et al. [6] have presented the effects of ageing conditions at various temperatures, load, sliding speed, and abrasive grit diameter in 6351 aluminium alloy have been investigated using artificial neural networks. The experimental results were trained in the ANN's program, and the results were compared with experimental values. It is observed that the experimental results coincided with ANN's results. Knowing friction coefficient is important for determination of wear loss conditions at Al-Si alloys. Nagaraj et al. [7] investigated the effects of load, sliding velocity and sliding duration on the wear loss of the alloy. The experimental results were used to train the ANN program and the results were compared with experimental values. It was observed that the experimental results are very close to ANN's results.

Kalidass et al. [8] focuses on two different models, regression mathematical and ANN models for predicting tool wear. Experiments have been conducted for measuring tool wear based on the design-of-experiment (DOE) technique in a vertical machining centre on AISI 304 steel using a solid carbide end mill cutter. The experimental values are used in Six Sigma software for finding the coefficients to develop the regression model. The experimentally measured values are also used to train the feedforward back-propagation ANN for the prediction of tool wear. Liujie et al. [9] used a back-propagation (BP) neural network to study the effects of the pv factor and sliding distance on the friction and wear behaviour of $30 \mathrm{wt}$. \% carbon fibre reinforced poly (ether-ether-ketone) advanced composite (PEEKCF30) at the contact temperature of $120{ }^{\circ} \mathrm{C}$. An experimental plan was performed on a pin-on-disc machine for obtained experimental results under unlubricated conditions. Hassan and Mohammed [10] experimentally investigated the parameters affecting the wear debris and the temperature rise due to friction, as well as developing the model ANN using MATLAB program for predicting the wear and temperature of disc and pad. Since the hybrid materials had not been enough researched, Sathyabalan et al. [11] have presented application of ANN on the MMC (hybrid LM6 aluminium), which is reinforced by $\mathrm{SiC}$ and flyash. The aim of this study was the prediction of the influence of additives (reinforcement materials) on the wear and hardness of hybrid material. The best results were obtained with ANN (4-6-2). Input parameters are defined by variables (flyash size, $\mathrm{SiC}$ size, flyash in $\%$ and $\mathrm{SiC}$ in \%) while the outputs are wear and hardness. Prediction accuracy was high, so the ANN has been validated for practical application by weight definition of the above-mentioned reinforcement materials for the hybrid material with good resistance against wear. An ANN model for the prediction of the wear process with glass-filled polytetrafluoroethylene (PTFE) composites is presented by Varade and Kharde [12]. An additional task of this research was establishing the dependence between load-sliding and time-sliding speed. The input parameters were velocity, load, time and percentage of glass fill, while the output was wear. Taguchi's orthogonal array of 27 experiments was used. The results revealed that the material with the highest percentage of glass fill possesses better resistance against wear. As the friction coefficient also depends on selected lubricant, Durak et al. [13] have presented a back-propagation neural network (BPNN) for the prediction of the concentration of the additive (based on PTFE) in the base oil in order to decrease the friction coefficient of the journal bearing. A bearing for testing was made of $\mathrm{ZnAl}$ alloy. The best results were obtained by using BPNN (3-5-1). Prediction accuracy is high, so the presented BPNN can be used in practice.

In order to research the applicability of the ANNs by friction coefficient prediction of the composite carbon-fibre-reinforced polymer (CGRP) material, Nasir et al. [14] have developed suitable ANN for this purpose. They have developed few different models, but the best results were with ANN (4-40-1), which used the Levenberg-Marquardt algorithm for training. The input parameters were fibre orientation, testing speed, normal force and duration time, while the output parameter was the friction coefficient.

Artificial intelligence (AI) has many tools and techniques that can be applied in the prediction of different parameters. One of these is the adaptive neuro-fuzzy inference system (ANFIS). This methodology was used in combination with experimental research [15]. This work focuses on 
establishing a correlation between friction coefficient and load by sliding bushing, made of a tin-based white metal alloy (TEGOTENAX V840). Experimental research [16] and [17] attempted to provide values (i.e., parameters), which will be used for ANFIS design: friction coefficient, speed and radial load. All mentioned values were measured in equal time intervals. The newly designed ANFIS was tested, and the results were compared, which showed that the prediction accuracy is high. As the final result, an expression was obtained that describes correlation friction coefficient - load under conditions of lubrication defined in advance.

The present study's objective was to predict friction coefficient in the radial hydrodynamic journal bearing of the white metal bearing alloys, known commercially as babbitt metal - Tegotenax V840, based on experimental research [16] and [17] using ANN.

\section{EXPERIMENTAL DETAILS AND PROCEDURE}

\subsection{Radial Journal Bearing Test Rig}

Fig. 1 shows a test rig for testing rotating machine elements, developed at the Faculty of Mechanical Engineering in Niš, Serbia, adapted for testing the tribological properties of plain bearings. The test rig for testing hydrodynamically lubricated plain bearings consists of three main systems: the drive system, the hydraulic system for realizing the load of the plain bearing, and the hydraulic system for lubricating the plain bearing.

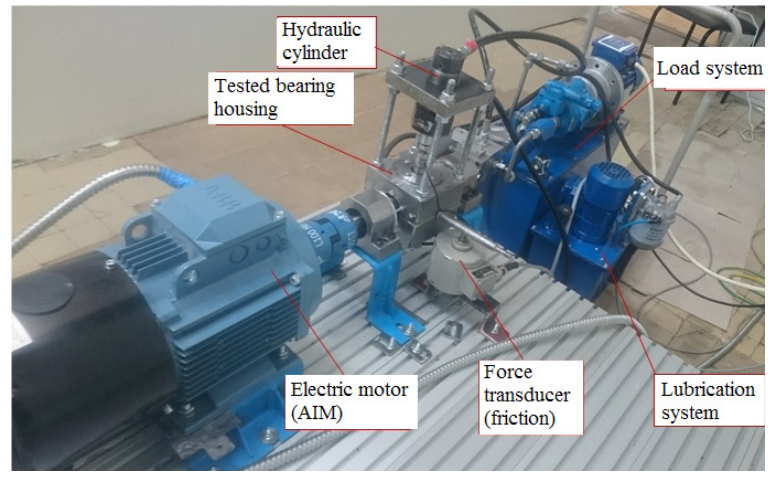

Fig. 1. Test rig

The drive system of the test rig consists of an asynchronous induction motor (ABB, $400 \mathrm{~V}, 50 \mathrm{~Hz}, 3$ $\mathrm{kW}, 1460 \mathrm{rpm}$ ), which is connected to the shaft by an elastic coupling. The shaft is supported by two roller bearings and a test specimen (i.e., a journal bearing mounted between these two bearings). The motor is equipped with an E720 encoder for counting the engine speed.

The test specimen-journal bearings are hydrodynamically lubricated. The lubrication system consists of an electric motor (1450 rpm, $90 \mathrm{~W})$, an ELP pump (AMGP-03C), and a 101 hydraulic tank. The lubricating oil of the test plain bearing is ISO VG 32. A schematic representation of the part of the test rig with the bearing assembly is shown in Fig. 2.

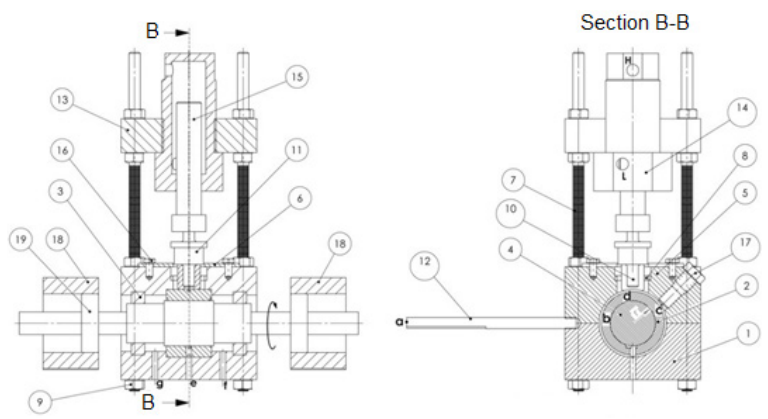

Fig. 2. The bearing-housing assembly (1-lower bracket; 2-sleeve; 3-seal; 4-shaft; 5-top bracket; 6-top cover with seal; 7-screw; 8-seal; 9-nut; 10-lever with which the bearing is loaded; 11-force sensor; 12-beam; 13-cylinder carrier; 14-cylinder; 15-piston; 16-screw; 17-thermocouple; 18-roller bearing housing; 19-roller bearing; a-place of friction force measurement; c- thermocouple temperature measurement location; $d$-place of bearing loading by radial force, g, e, f- hydraulic ports)

A hydraulic system was used to load the sliding bearing, which consists of an electric motor (EM) $(0.75 \mathrm{~kW}, 380 \mathrm{~V}, 1420 \mathrm{rpm})$, a pump (EATON PVQ10), and a 301 oil tank. The hydraulic cylinder is used to load the test of a sliding bearing. The working fluid is the above-mentioned oil. The hydraulic cylinder exerts a load on the journal bearing sleeve via a radial force sensor (HBM U9C / $10 \mathrm{kN}$ ).

Table 1 shows the properties of the operating fluid.

Table 1. Properties of hydraulic oil ISO VG32

\begin{tabular}{lccc}
\hline Item & & Value & Unit \\
\hline Density at $15.6{ }^{\circ} \mathrm{C}$ & $\rho$ & 868 & $\mathrm{~kg} / \mathrm{m}^{3}$ \\
\hline Kinematic viscosity at $40{ }^{\circ} \mathrm{C}$ & $v_{40}$ & 32.2 & $\mathrm{~mm}^{2} / \mathrm{s}$ \\
\hline Kinematic viscosity at $100{ }^{\circ} \mathrm{C}$ & $v_{100}$ & 5.52 & $\mathrm{~mm}^{2} / \mathrm{s}$ \\
\hline Viscosity index & & 108 & - \\
\hline Flash point & 212 & ${ }^{\circ} \mathrm{C}$ \\
\hline Pour point & -33 & ${ }^{\circ} \mathrm{C}$ \\
\hline Aniline point & 104 & ${ }^{\circ} \mathrm{C}$ \\
\hline
\end{tabular}

The bearing sleeve is given in Fig. 3. The dimensions of the bearing are: bearing diameter $d=40 \mathrm{~mm}+0.05 \mathrm{~mm}$, bearing axial length $B=40 \mathrm{~mm}$, 
outer bearing diameter $D=60 \mathrm{~mm}$, bearing diametral clearance $Z=0.025 \mathrm{~mm}$.
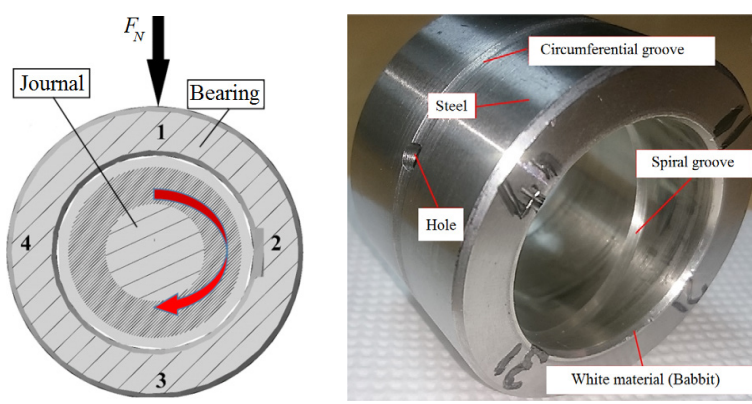

Fig. 3. Bearing sleeve

\subsection{Preparation of Experimental Materials and Conditions}

The journal bearing sleeve is made of AISI 440C stainless steel, and a $3 \mathrm{~mm}$ thick layer of white metal (Tegotenax V840) is applied to the sleeve. The shaft is made of AISI $440 \mathrm{C}$ stainless steel. The chemical properties of the steel layer and Babbitt layer materials are given in Table 2, and the mechanical and physical properties in Table 3.

Table 2. Chemical composition of AISI $440 \mathrm{C}$ sleeve and material of internal sliding surface - white metal TEGOTENAX V840

\begin{tabular}{ccc}
\hline Element & TEGOTENAX V840 [wt. \%] & AISI 440C [wt. \%] \\
\hline $\mathrm{Sn}$ & 88.7 & - \\
\hline $\mathrm{Sb}$ & 7.6 & - \\
\hline $\mathrm{Cu}$ & 3.7 & - \\
\hline $\mathrm{C}$ & - & 1.2 \\
\hline $\mathrm{Si}$ & - & 1 \\
\hline $\mathrm{Mn}$ & - & 1 \\
\hline $\mathrm{Ni}$ & - & 1 \\
\hline $\mathrm{Cr}$ & - & 18 \\
\hline $\mathrm{Mo}$ & - & 0.75 \\
\hline $\mathrm{P}$ & - & 0.04 \\
\hline $\mathrm{S}$ & - & 0.03
\end{tabular}

Table 3. Mechanical and Physical Properties

\begin{tabular}{lccc}
\hline & \multicolumn{2}{c}{$\begin{array}{c}\text { Tin-based white metal } \\
\text { alloy: TEGOTENAX V840 }\end{array}$} & $\begin{array}{c}\text { Shaft: AISI } \\
\text { 440C }\end{array}$ \\
\hline & $20^{\circ} \mathrm{C}$ & 23 & 269 \\
\cline { 2 - 4 } Hardness HB 10/250/180 & $50^{\circ} \mathrm{C}$ & 17 & - \\
\cline { 2 - 4 } & $100^{\circ} \mathrm{C}$ & 10 & - \\
\cline { 2 - 4 } & $150^{\circ} \mathrm{C}$ & 8 & - \\
\hline Yield Strength, $R_{p 0.2}[\mathrm{MPa}]$ & \multicolumn{4}{c}{46} & 448 \\
\hline Tensile Strength, $R_{m}[\mathrm{MPa}]$ & \multicolumn{2}{c}{77} & 758 \\
\hline Young's modulus, $E[\mathrm{MPa}]$ & \multicolumn{2}{c}{56500} & 200000 \\
\hline Density, $\rho\left[\mathrm{kg} / \mathrm{m}^{3}\right]$ & \multicolumn{2}{c}{7400} & 7650 \\
\hline Poisson ratio, $v$ & \multicolumn{2}{c}{0.33} & 0.27 to 0.30 \\
\hline
\end{tabular}

\subsection{Determination of Frictional Properties}

The friction coefficient is determined by the moment of friction. The friction moment $M_{f}(t)$ as a function of time is calculated as the product of the friction force $F_{f}(t)$ and the bearing radius $r$. As a reaction of the friction moment, the force $F_{s}(t)$ appears at the contact point of the force sensor, which is at a perpendicular distance $L$ from the centre of the sleeve (Fig. 4).

$$
M_{f}(t)=F_{f}(t) \cdot r=F_{s}(t) \cdot L .
$$

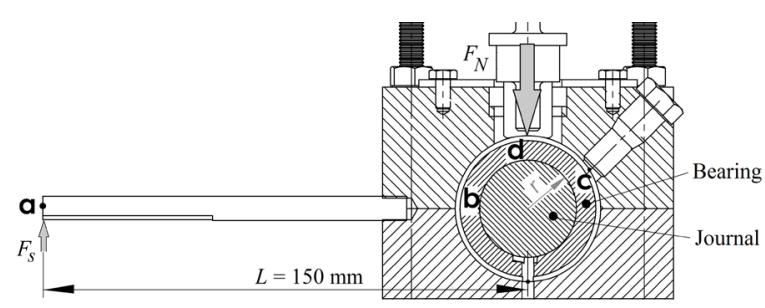

Fig. 4. Friction force measurement scheme

Based on the expression for determining the friction force:

$$
F_{f}(t)=\mu(t) \cdot F_{N}(t) .
$$

The friction coefficient is determined by the expression:

$$
\mu(t)=\frac{F_{f}(t)}{F_{N}(t)}=\frac{F_{s}(t) \cdot L}{r \cdot F_{N}(t)} .
$$

The input parameters of the test are speed $n$, i.e., sliding speed $v$ and bearing load $F_{N}$. The radial bearing load was varied in the range $F_{N}=1000 \mathrm{~N}$ to $4000 \mathrm{~N}$, with the variation of the shaft speeds in the range $n=1000 \mathrm{rpm}$ to $3000 \mathrm{rpm}$. The test parameters

\begin{tabular}{|c|c|c|c|}
\hline $\begin{array}{l}\text { Speed, } n \\
\text { [rpm] }\end{array}$ & $\begin{array}{l}\text { Sliding speed, } \\
\qquad v[\mathrm{~m} / \mathrm{s}]\end{array}$ & $\begin{array}{c}\text { Bearing load, } \\
F_{N}[\mathrm{~N}]\end{array}$ & $\begin{array}{l}\text { Specific bearing load, } \\
p=F_{N} /(d \cdot B)[\mathrm{MPa}]\end{array}$ \\
\hline \multirow{4}{*}{1000} & \multirow{4}{*}{2.09} & 1000 & 0.625 \\
\hline & & 2000 & 1.25 \\
\hline & & 3000 & 1.875 \\
\hline & & 4000 & 2.5 \\
\hline \multirow{4}{*}{2000} & \multirow{4}{*}{4.2} & 1000 & 0.625 \\
\hline & & 2000 & 1.25 \\
\hline & & 3000 & 1.875 \\
\hline & & 4000 & 2.5 \\
\hline \multirow{4}{*}{3000} & \multirow{4}{*}{6.3} & 1000 & 0.625 \\
\hline & & 2000 & 1.25 \\
\hline & & 3000 & 1.875 \\
\hline & & 4000 & 2.5 \\
\hline
\end{tabular}
and specific bearing load are given in Table 4.

Table 4. Defined parameters for testing plain bearings 
For data acquisition within the experimental tests of tribological properties of the sliding bearing, a personal computer (PC) equipped with appropriate hardware (measuring and control interface) in conjunction with software developed in the LabVIEW environment is used. The data was transmitted to the recorder, which enabled monitoring and recording of the signals. The data about coefficient friction, radial load and sensor force were applied for $1 / 20 \mathrm{~s}$ and the temperature lubrication oil and load for $5 \mathrm{~s}$.

\subsection{Test Results}

Based on the experimental plan given in Table 4, tests were performed on test specimens of plain bearings with a previously defined geometry.

Figs. 5 to 7 show the changes of temperature and friction coefficient with the change of the radial load of the bearing $F_{N}=1000 \mathrm{~N}$ to $4000 \mathrm{~N}$ and the speed $n=1000 \mathrm{rpm}$ to $3000 \mathrm{rpm}$. Twelve different experiments were performed, each lasting an average of 5 hours (18000 s).

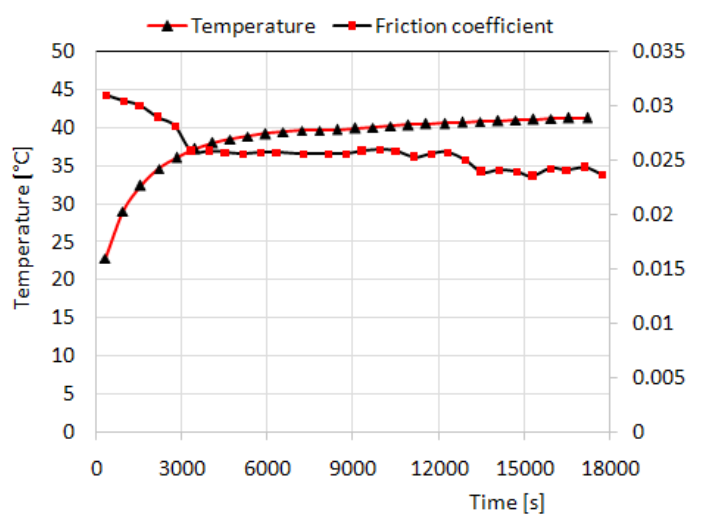

a)

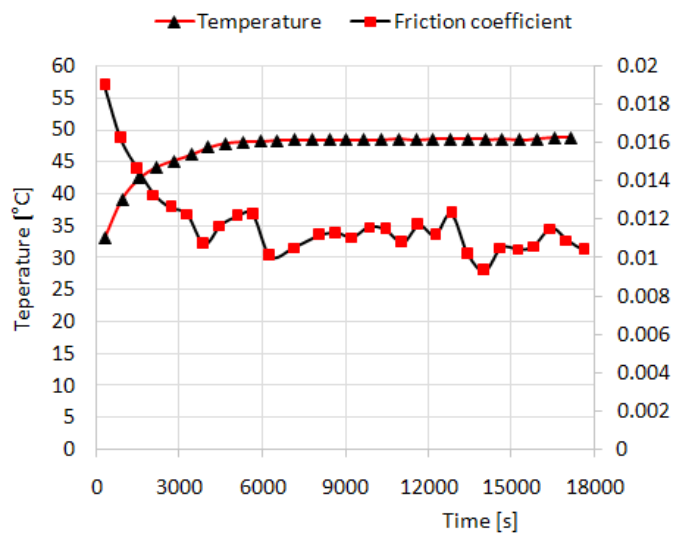

\section{ANN MODEL DEVELOPMENT}

In order to establish a mathematical relationship between the dependence of the experimental parameters of the journal bearing test in the conditions of hydrodynamic testing, two ANN models were developed. The first model was for the prediction of the friction coefficient, and the second was for the prediction of the bearing temperature. For training and testing of the network, the data of the measured values of the friction coefficient $\mu$ and the bearing temperature $T$ for $18000 \mathrm{~s}$ were used as a function of the change of the radial load $F_{N}$ and the speed of the shaft $n$.

The neural network architecture for both models had three neurons in the input layer (bearing load $F_{N}$, speed $n$ and time $t$ ), one neuron in the output layer (friction coefficient $\mu$ respectively bearing temperature $T$ ) and one hidden layer with 6 neurons (Fig. 8).

For the ANN model, a linear activation function and a nonlinear sigmoid activation function were combined in the output and hidden layers,
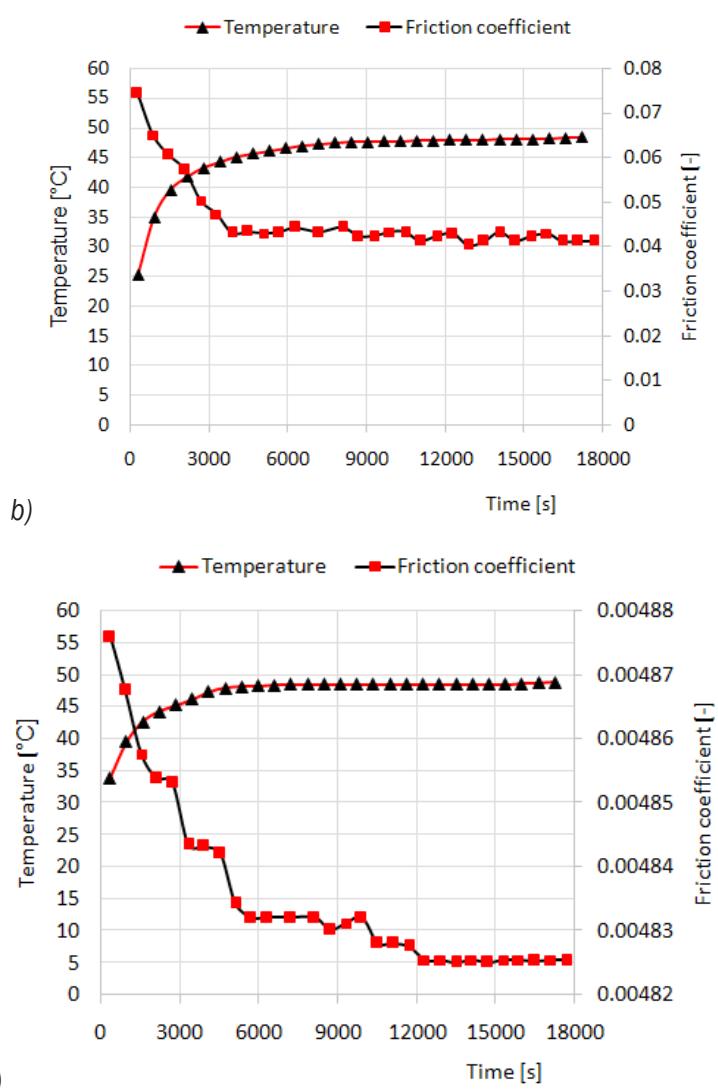

Fig. 5. Trends in time of friction coefficient and bearing temperature at $1000 \mathrm{rpm}$ speed, for a load of a) $F_{N}=1000 \mathrm{~N}$; b) $F_{N}=2000 \mathrm{~N}$; c) $F_{N}=3000 \mathrm{~N}$ and d) $F_{N}=4000 \mathrm{~N}$ 


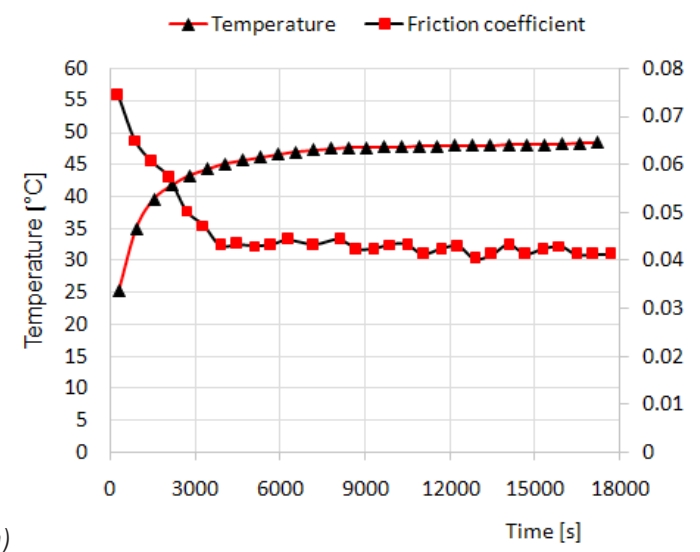

a)

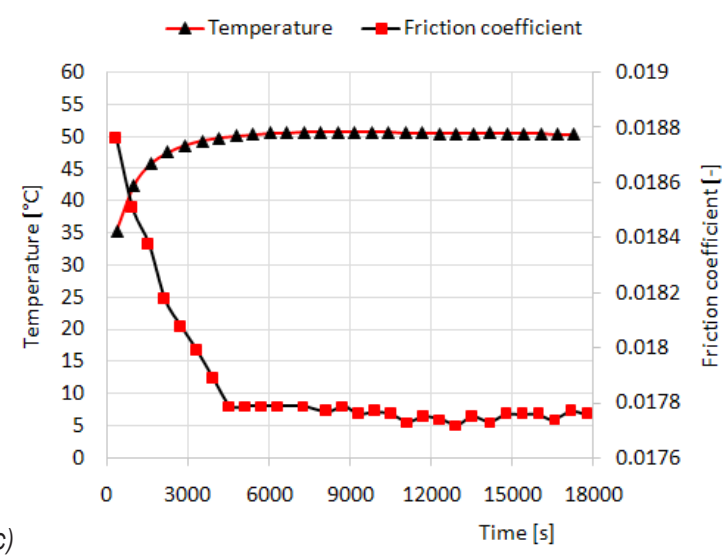

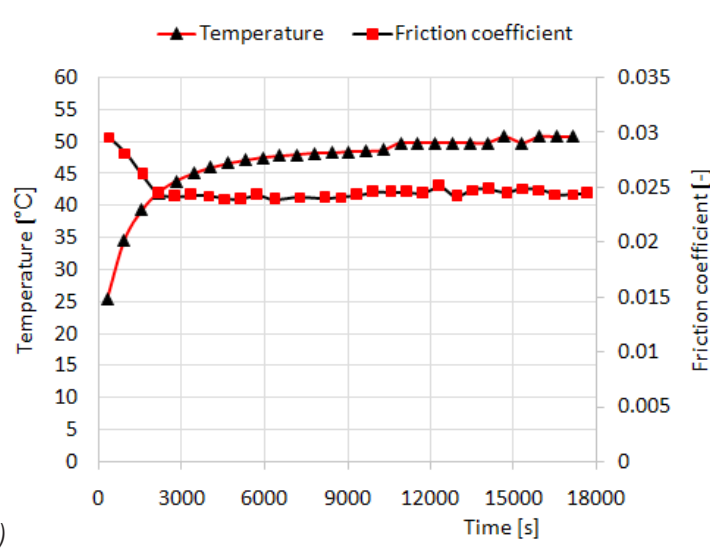

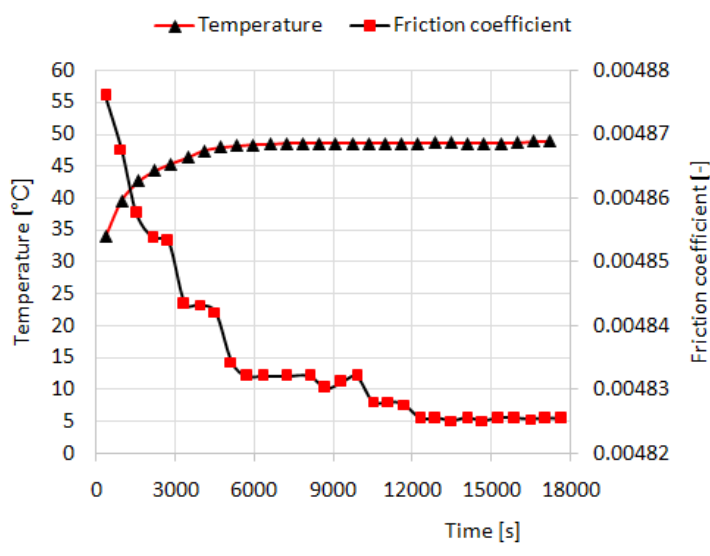

d)

Fig. 6. Trends in time of friction coefficient and bearing temperature at $2000 \mathrm{rpm}$ speed, for a load of a) $F_{N}=1000 \mathrm{~N}$; b) $F_{N}=2000 \mathrm{~N}$; c) $F_{N}=3000 \mathrm{~N}$ and d) $F_{N}=4000 \mathrm{~N}$

respectively. Accordingly, the obtained experimental data were normalized in the range $[-1,1]$. During the development of the ANN model, the available input/ output data set was randomly divided into two sets: a training set and a test set for the ANN network model. 295 data points were used for ANN training, and 43 data points were used to test trained ANN network models.

The Levenberg-Marquardt algorithm was chosen for ANN training due to its high accuracy and fast convergence. In order to solve the convergence problem and minimize, as well as slow the convergence, the ANN training process was repeated several times with the help of different initial weights established by the Nguyen-Widrow method. During the ANN training process, although the maximum number of training iterations was set at 1000 , it was observed that much fewer iterations were sufficient to train ANN models, Fig. 9.

Upon completion of the training process, the prediction performance of the trained ANN model was assessed. For this purpose, the mean absolute percentage error (MAPE) was calculated according to the Eq (4):

MAPE $=\frac{1}{N} \sum_{N}\left|\frac{\text { Experimental value }- \text { Estimed value }}{\text { Experimental value }}\right| \cdot 100[\%],(4)$

where $N$ is the number of data.

The average errors for training and testing data for the first model are $0.0054 \%$ and 0.0085 $\%$, respectively, which are very small indeed. The average errors for training and testing data for the second model are $0.12 \%$ and $0.023 \%$, respectively, which are very small.

\section{ANALYSIS AND DISCUSSION}

Fig. 10 shows the prediction of the friction coefficient as a function of bearing load and speed for the white metal alloy bearing internal sliding surface of Tegotenax V840. The prediction of the friction coefficient of the sliding bearing's internal surface made of tin-based white metal alloy showed that the 

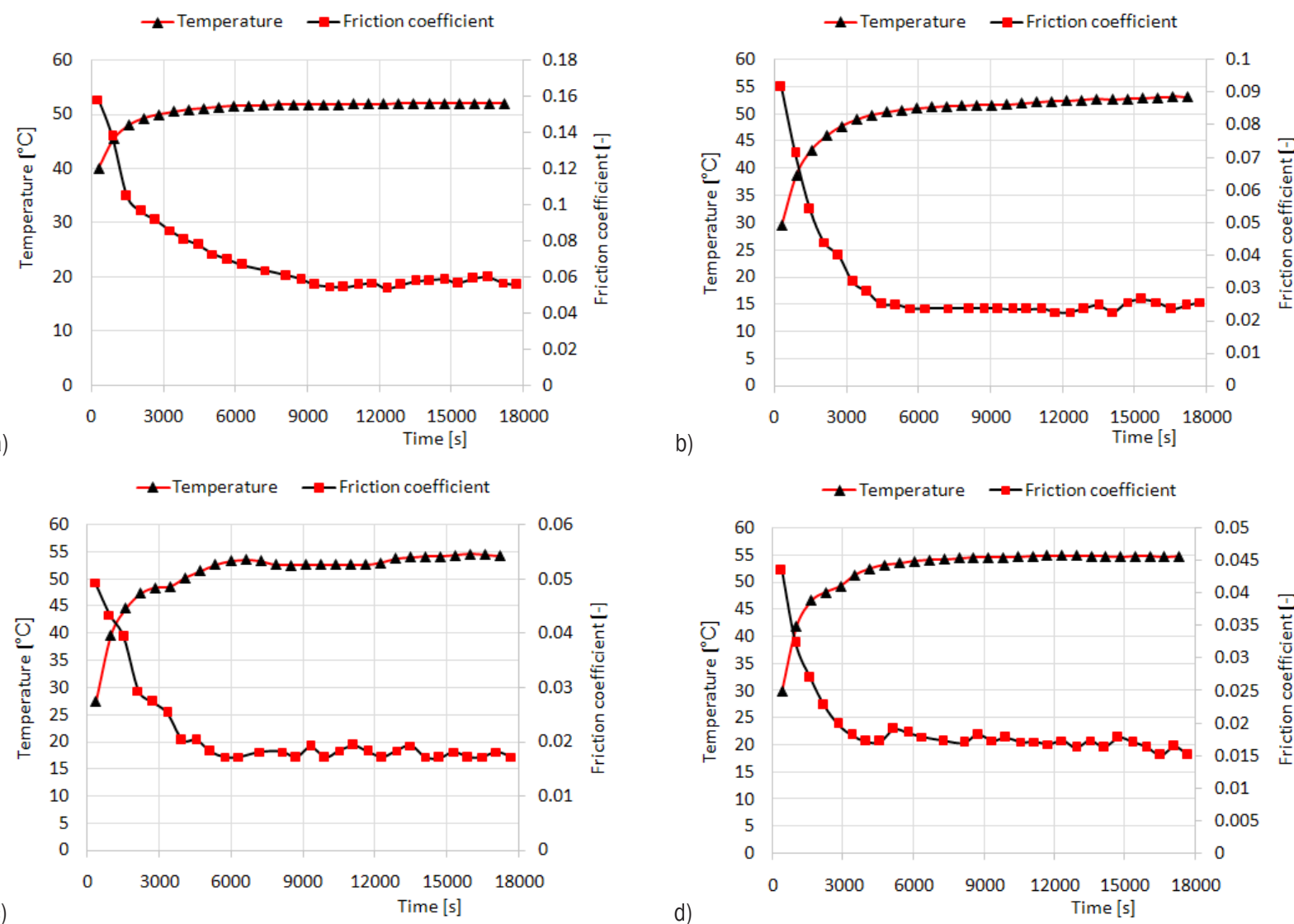

Fig. 7. Trends in time of friction coefficient and bearing temperature at $3000 \mathrm{rpm}$ speed, for a load of a) $F_{N}=1000 \mathrm{~N}$; b) $F_{N}=2000 \mathrm{~N}$; c) $F_{N}=3000 \mathrm{~N}$ and d) $F_{N}=4000 \mathrm{~N}$

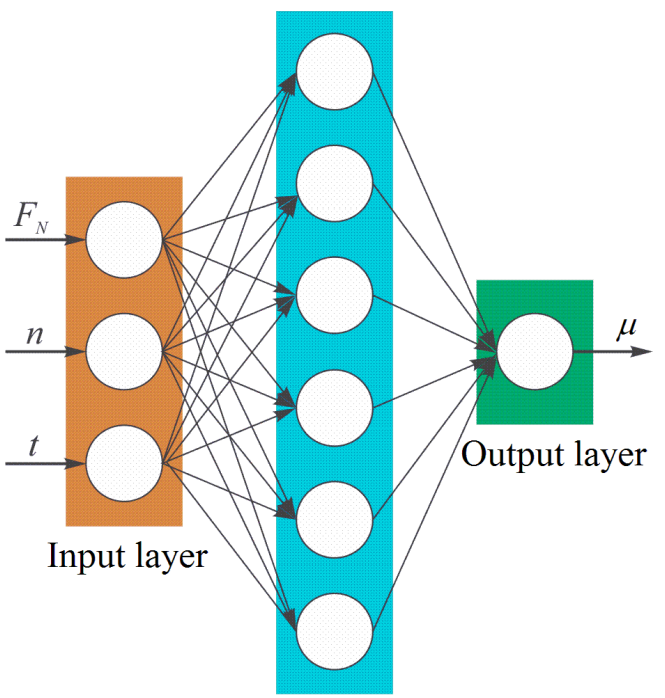

Hidden layer

Fig. 8. Neural network architecture

friction coefficient has a downward trend with an increased bearing load.

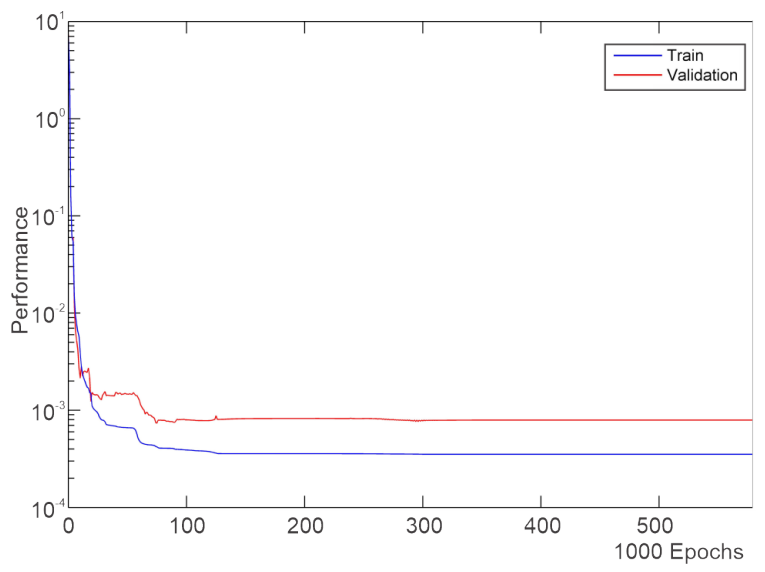

Fig. 9. Minimized mean squared error (MSE) during the ANN training process for friction coefficient prediction

The values of the change of the friction coefficient take the form of a downward trend - curve with increasing bearing load and decreasing speed, as shown in Fig. 10. 


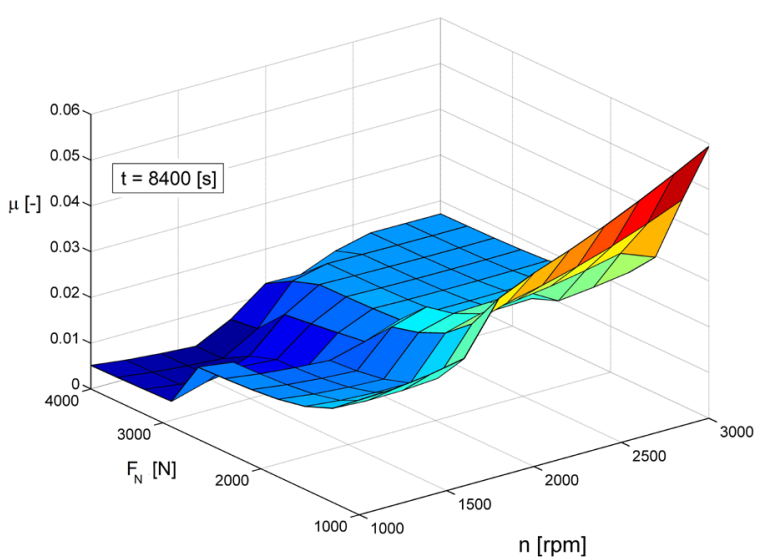

Fig. 10. Prediction of friction coefficient $\mu$ as a function of bearing load $F_{N}$ and speed $n$ with the help of BP neural network
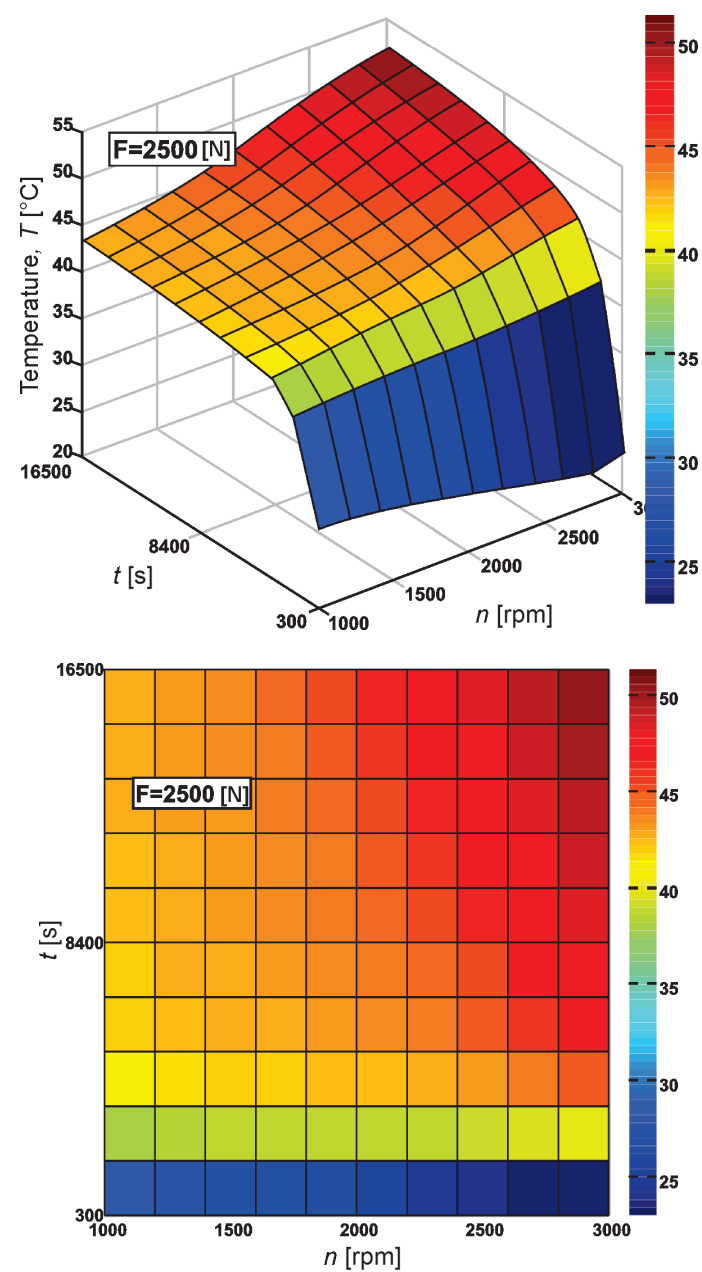

Fig. 11. Prediction of bearing temperature $T$ as a function of speed $n$ and sliding time $t$ with the help of BP neural network

The sliding friction between the shaft sleeve, bearing, and lubricant causes an increase in the lubricant temperature, which results in a decrease in the shear stress of the lubricant, which leads to a decrease in the viscosity of the lubricant and hence a decrease in the friction coefficient.

Fig. 11 shows the prediction of bearing temperature $T$ as a function of the speed $n$ and a sliding time $t$ for the bearing load $F_{N}=2500 \mathrm{~N}$. This change has a growing trend with an increasing sliding time and speed.

It can be seen that the bearing temperature $T$ increases with time $t$, as shown in Fig. 11. As the friction coefficient is directly proportional to the dynamic viscosity $\eta$, and the increase in oil temperature leads to a decrease in dynamic viscosity, which certainly leads to a decrease in friction coefficient. In Fig. 11, two zones can be observed, the unstable zone and the stable zone. In the zone of an unstable state, the temperature inside the system increases with time. The duration of this zone is estimated at about $4000 \mathrm{~s}$. The second zone is a stable state in which the temperature remains approximately constant: somewhere around $41{ }^{\circ} \mathrm{C}$ to $54{ }^{\circ} \mathrm{C}$.

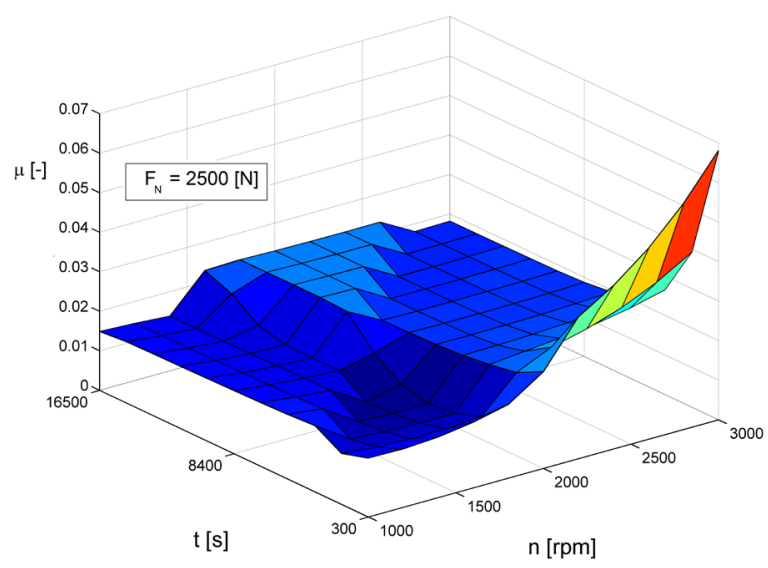

Fig. 12. Prediction of the ratio of the friction coefficient $\mu$, in relation to the speed $n$ and the sliding time $t$ with the help of $B P$ neural network

Fig. 12 shows the predicted friction coefficient $\mu$ in relation to the speed $n$ and the sliding time $t$ at constant load $F_{N}=2500 \mathrm{~N}$. It can be seen that the friction coefficient $\mu$ increases with the speed $n$. As the sliding time increases, the friction coefficient decreases according to the increase in temperature and the decrease in the viscosity of the oil.

The optimization of the ANN model using metaheuristics indicated a maximum friction coefficient of 0.1513, which was obtained in a combination of values of process parameters: $n=$ $3000 \mathrm{rpm}, F_{N}=1072 \mathrm{~N}$ and $t=300 \mathrm{~s}$. With regard to 
the stochastic nature of metaheuristics, i.e., inability to guarantee the optimality of the found solution, the solution was checked by creating a three-dimensional (3D) diagram of the friction coefficient for $t=300 \mathrm{~s}$, which is shown in Fig. 13.

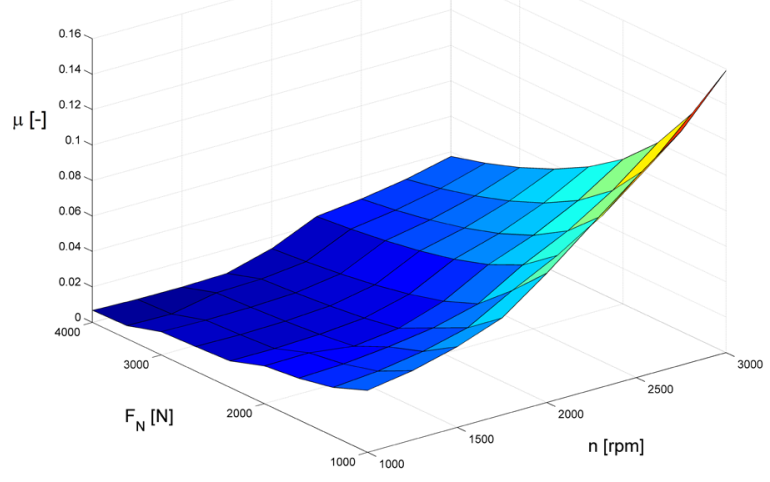

Fig. 13. The highest friction coefficient $\mu$, obtained by optimizing the ANN model

As can be seen from Fig. 13, the value of the maximum friction coefficient of 0.1591 is obtained in a combination of the force $F_{N}=1000 \mathrm{~N}$ and the speed $n=3000 \mathrm{rpm}$.

Based on experimental data, it was determined that for $F_{N}=1000 \mathrm{~N}, n=3000 \mathrm{rpm}$ and $t=300 \mathrm{~s}$, the resulting coefficient of friction has a value of 0.1579 , which once again confirms the accuracy of the created ANN model.

\section{CONCLUSIONS}

The research into tribological properties of sliding bearings was performed on the originally developed equipment for testing rotating elements at the Faculty of Mechanical Engineering in Niš in the Laboratory for Mechanical Constructions, Development, and Engineering. A bearing made of tin-based white metal alloy-TEGOTENAX V840 were tested under hydrodynamic lubrication conditions with selected ISO VG 32 hydraulic oil.

Based on the conducted experimental research and developed ANN models for the prediction of the friction coefficient (first model) and bearing temperature (second model), the following conclusions can be drawn:

The ANN architecture for both models was 3-6-2, and the Levenberg-Marquardt algorithm was used to train the ANN. The result of ANN prediction shows that the models are extremely good with minimal mean square error training and testing data for the first model $0.0054 \%$ and $0.0085 \%$ and for the second model $0.12 \%$ and $0.023 \%$, respectively.

The optimization of the ANN model, the highest friction coefficients 0.1513 were obtained at a bearing load of $1072 \mathrm{~N}$ and a speed of $3000 \mathrm{rpm}$, while the lowest coefficients of friction 0.00288 were obtained at a maximum load of $4000 \mathrm{~N}$ and a speed of 1675.22 rpm.

The bearing temperature prediction model indicates a growing trend of change with increasing sliding time and speed. The bearing temperature $\mathrm{T}$ increases with time t; after a little more than 1 hour (about $4000 \mathrm{~s}$ ), the bearing temperature stabilizes at approximately $50{ }^{\circ} \mathrm{C}$ at all bearing loads and all bearing rotation frequencies.

\section{ACKNOWLEDGEMENT}

This research was financially supported by the Ministry of Education, Science and Technological Development of the Republic of Serbia (Contract No. 451-03-9/2021-14/200109).

\section{REFERENCES}

[1] Chowdhury, M.A., Nuruzzaman, D.M., Mia, A.H., Rahaman, M.L. (2012). Friction coefficient of different material pairs under different normal loads and sliding velocities. Tribology in Industry, vol. 34, no. 1, p. 18-23.

[2] Nuruzzaman, D.M., Chowdhury, M.A., Rahaman, M.L. (2011). Effect of duration of rubbing and normal load on friction coefficient for polymer and composite materials. Industrial Lubrication and Tribology, vol. 63, no. 5, p. 320-326, DOI:10.1108/00368791111154931.

[3] Wu, H., Bi, Q., Zhu, S., Yang, J., Liu, W. (2011). Friction and wear properties of Babbitt alloy 16-16-2 under sea water environment. Tribology International, vol. 44, no. 10, p. 11611167, D0I:10.1016/j.triboint.2011.05.007.

[4] Zeren, A., Feyzullahoglu, E., Zeren, M. (2007). A study on tribological behaviour of tin-based bearing material in dry sliding. Materials \& Design, vol. 28, no. 1, p. 318-323, D0I:10.1016/j.matdes.2005.05.016.

[5] Asafa, T., Fadare, D.A. (2012). Artificial neural network predictive modeling of uncoated carbide tool wear when turning NST 37.2 steel. Journal of Engineering and Applied Sciences, vol. 7, no. 4, p. 396-406.

[6] Durmuş, H.K., Özkaya, E., Meric, C. (2006). The use of neural networks for the prediction of wear loss and surface roughness of AA 6351 Aluminum Alloy. Materials \& Design, vol. 27, no. 2, p. 156-159, D0I:10.1016/j.matdes.2004.09.011.

[7] Nagaraj, A., Shivalingappa, D., Koti, H., Channankaiah (2012). Modeling and predicting adhesive wear behaviour of aluminium-silicon alloy using neural networks. International Journal of Recent Scientific Research, vol. 3, no. 5, p. 378381. 
[8] Kalidass, S., Palanisamy, P., Muthukumaran, V. (2012). Prediction of tool wear using regression and artificial neural network models in end milling of AISI 304 austenitic stainless steel. International Journal of Engineering and Innovative Technology (IJEIT), vol. 1, no. 2, p. 29-36.

[9] Liujie, X., Cardoso, R., Davim, J.P. (2008). Modelling of tribological behaviours of composite PEEK-CF30 using BP neural networks. Materials Science-Poland, vol. 26, no. 3, p. 495-504.

[10] Hassan, A.K.F., Mohammed, S. (2016). Artificial neural network model for estimation of wear and temperature in pindisc contact. Universal Journal of Mechanical Engineering, vol. 4, no.2, p. 39-49, D0l:10.13189/ujme.2016.040204.

[11] Sathyabalan, P., Selladurai, V., Sakthivel, P. (2009). ANN based prediction of effect of reinforcements on abrasive wear loss and hardness in a hybrid MMC. American Journal of Engineering and Applied Sciences, vol. 2, no. 1, p. 50-53, DOI:10.3844/ajeassp.2009.50.53.

[12] Varade, B.V., Kharde, Y.R. (2012). Prediction of specific wear rate of glass filled PTFE composites by artificial neural networks and Taguchi approach. International Journal of Engineering Research and Applications, vol. 2, no. 6, p. 679683.

[13] Durak, E., Salman, Ö., Kurbanoglu, C. (2008). Analysis of effects of oil additive into friction coefficient variations on journal bearing using artificial neural network. Industrial Lubrication and Tribology, vol. 60, no. 6, p. 309-316, DOI:10.1108/00368790810902241.

[14] Nasir, T., Yousif, B.F., McWilliam, S., Salih, N.D., Hui, L.T. (2010). An artificial neural network for prediction of the friction coefficient of multi-layer polymeric composites in three different orientations. Proceedings of the Institution of Mechanical Engineers, Part C: Journal of Mechanical Engineering Science, vol. 224, no. 2, p. 419-429, DOI:10.1243/09544062JMES1677.

[15] Anđelković, B., Al-Sammarraie, A., Milčić, D., Stamenković, D., Banić, M., Marinović, J.S., Đorđević, B., Zdravković, N. (2018). Consideration of the use of artificial intelligence methods for determining the friction coefficient of lubricated sliding bearings. IOP Conference Series: Materials Science and Engineering, vol. 393, D0l:10.1088/1757899X/393/1/012063.

[16] Al-Sammarraie, A., Milčić, D., Banić, M., Milčić, M. (2017). Tribological behavior of radial plain bearing made of TiNbased white metal alloy- Tegotenax V840. 15th International Conference on Tribology, p. 258-266.

[17] Al Sammarraie, A., Milčić, D., Banić, M., Milčić, M. (2018). Tribological behavior of Tin- based materials - Tegotenax V840 in oil lubricated conditions. Annals of Faculty Engineering Hunedoara, vol. 16, no.1, p.149-152. 